\title{
ShMOLLI and 5(4R) 3 MOLLI T1 mapping in HCM detect similar ECV despite a difference in absolute $\mathrm{T} 1$ measurements
}

\author{
Jorge A Gonzalez ${ }^{1 *}$, Peter Shaw ${ }^{1}$, Yang Yang ${ }^{2}$, Christopher M Kramer ${ }^{1,3}$, Michael Salerno ${ }^{1,3}$ \\ From 18th Annual SCMR Scientific Sessions \\ Nice, France. 4-7 February 2015
}

\section{Background}

T1 mapping and extracellular volume (ECV) measurements enable assessment of diffuse fibrosis in HCM and have been validated against histology. There still remains wide variation in pulse sequences used to measure $\mathrm{T} 1$ each with their associated limitations and biases in $\mathrm{T} 1$ determination. We sought to compare $\mathrm{T} 1$ values and ECV measurements between a 5(4R)3 variant of MOLLI and ShMOLLI in patients undergoing CMR for evaluation of hypertrophic cardiomyopathy (HCM).

\section{Methods}

CMR imaging was performed in 11 patients with HCM on a 1.5T Avanto (Siemens) scanner under an IRB approved protocol. T1 maps were acquired pre contrast, 5,15 and 30 minutes post $0.15 \mathrm{mmol} / \mathrm{kg}$ of Gd contrast using both ShMOLLI and MOLLI pulse sequences. Sequence parameters included: TE/TR/FA $1.1 \mathrm{~ms} / 2.5 \mathrm{~ms} / 35^{\circ}, \mathrm{FOV}=340$ x 260 , resolution $1.8 \mathrm{~mm} \times 1.8 \mathrm{~mm}$, thickness $8 \mathrm{~mm}$. Regions of interest were drawn in the LV blood pool and myocardium and the mean, SD and coefficient of variation T1 values were determined. Partition coefficient $(\lambda)$ and ECV were determined from all available time points.

Additionally images were acquired in an agarose gel phantom with T1s ranging from 300 to $1400 \mathrm{~ms}$. Reference T1s were determined using a spin echo pulse sequence.

\section{Results}

Table 1 shows the comparison of T1s, $\lambda$, and ECV between ShMOLLI and MOLLI. T1s differed between techniques for all but the pre-contrast blood measurements. Correlation and Bland Altman Analysis (Fig 1) demonstrate a slope of $0.98\left(\mathrm{R}^{2}=0.99\right)$ and a bias of $47 \mathrm{~ms}$ (MOLLI>ShMOLLI) across all time points. This bias was similar to the $33 \mathrm{~ms}$ bias between the techniques in the phantom experiment. The coefficient of variation of T1 measurements for MOLLI and ShMOLLI were similar (0.063 and 0.031 versus 0.067 and 0.027$)$ for myocardium and blood, respectively, indicating similar uncertainty in the measured T1 times. Notably the $\lambda$ and ECV were similar between the techniques. With the given bias in T1 measurements a $2 \%$ bias in ECV measurements was calculated, explaining why both techniques yield similar ECV despite significant differences in $\mathrm{T} 1$.

\section{Conclusions}

T1s from ShMOLLI and MOLLI were highly correlated $(\mathrm{R}=0.999)$ however there was a $47 \mathrm{~ms}$ bias (MOLLI $>\mathrm{Sh}-$ MOLLI) between techniques. Importantly, both methods yielded equivalent ECV measurements in HCM.

\section{Funding}

K23 HL112910 (MS).

T32 EB003841 (JG, PS).

\section{Authors' details}

${ }^{1}$ Cardiology, University of Virginia, Charlottesville, VA, USA. 'Biomedical Engineering, University of Virginia, Charlottesville, VA, USA. ${ }^{3}$ Radiology, University of Virginia, Charlottesville, VA, USA.

'Cardiology, University of Virginia, Charlottesville, VA, USA

Full list of author information is available at the end of the article 
Table 1 Comparison of T1, $\lambda$ and ECV

\begin{tabular}{cccc}
\hline & ShMOLLI (msec) & MOLLI (msec) & P-value \\
\hline T1 Myo (Pre) & 964.1 ms (66.9) & $1004.6(72.4)$ & $<0.001$ \\
\hline T1 Blood (Pre) & $1502.3(40.4)$ & $1529.6(39.1)$ & 0.43 \\
\hline T1 Myo (5 min) & $385.1(30)$ & $429.5(20)$ & $<0.001$ \\
\hline T1 Blood (5 min) & $262.3(6.3)$ & $298.5(10)$ & $<0.001$ \\
\hline T1 Myo (15 min) & $459(29.2)$ & $496(27.6)$ & $<0.001$ \\
\hline T1 Blood (15 min) & $341.4(9.6)$ & $355.3(12.3)$ & 0.03 \\
\hline T1 Myo (30 min) & $518.3(27.9)$ & $422.7(12.4)$ & $<0.001$ \\
\hline T1 Blood (30 min) & $444.1(13.3)$ & $<0.001$ \\
\hline$\lambda$ (Lambda) & $556.3(32.3)$ & $0.50(0.06)$ & 0.08 \\
\hline ECV & $0.49(0.06)$ & $0.30(0.03)$ & 0.08 \\
\hline
\end{tabular}
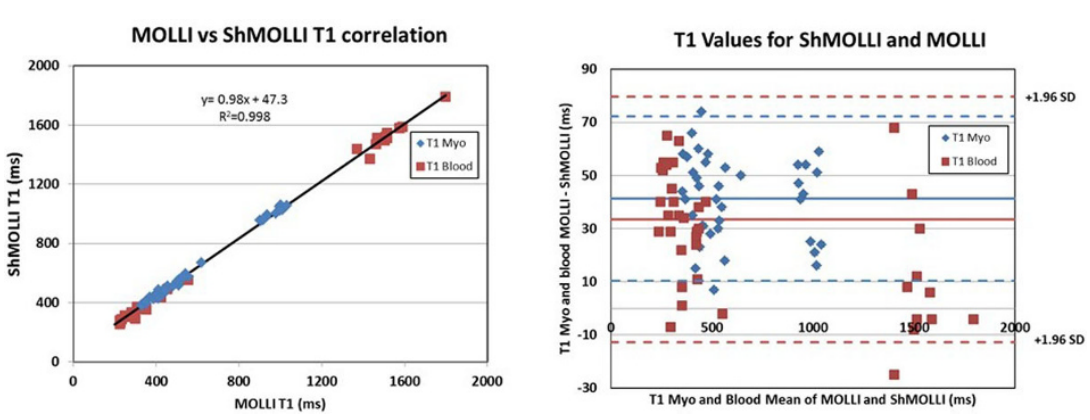

Figure 1

Published: 3 February 2015

doi:10.1186/1532-429X-17-S1-P326

Cite this article as: Gonzalez et al: ShMOLLI and 5(4R) 3 MOLLI T1

mapping in HCM detect similar ECV despite a difference in absolute T1

measurements. Journal of Cardiovascular Magnetic Resonance 201517

(Suppl 1):P326

Submit your next manuscript to BioMed Central and take full advantage of:

- Convenient online submission

- Thorough peer review

- No space constraints or color figure charges

- Immediate publication on acceptance

- Inclusion in PubMed, CAS, Scopus and Google Scholar

- Research which is freely available for redistribution

Submit your manuscript at www.biomedcentral.com/submit 